\title{
The improvement on thermal performance of herbal ball compress
}

\author{
Wasan Kamsanam ${ }^{1, a}$ and Rachaneewan Aungkurabrut ${ }^{1}$ \\ ${ }^{1}$ Mechanical Engineering Department, School of Engineering, University of Phayao, 56000, Thailand
}

\begin{abstract}
Herbal ball compress is an equipment usually employed in Thai traditional medical treatment to relieve muscular pain. The herbal ball needs to be prepared by steam heating prior to the application in order to extract essential oils from herbal ingredients. This study aims at improving thermal performance of herbal ball so that it can maintain temperature at a suitable level for a particular period of time. In this article, the investigation to facilitate the herbal ball compress usage is performed in various schemes. Adding some materials of high specific heat capacity is one approach. In addition, employing electric powered heat sources such as cable heater, Peltier sheet, ceramic resistor and directly supplied steam are also included in the test. The experimental results revealed that the herbal ball with small water balloons inside can prolong the time duration at a desired temperature range. Direct steam supply system was built by modifying a household electric pan. The experiment demonstrated that the temperature of herbal ball was capably controlled at a desired level through the treatment. It is supposed that the appropriate method could benefit thermal performance of herbal ball compress in regard to temperature control, treatment duration, economical aspect as well as safety circumstance.
\end{abstract}

\section{Introduction}

Herbal ball compress has been widely used as a traditional therapeutics in Thai community for centuries [1]. Nowadays, usage of herbal ball compress either at home for personal remedies or at spa services has been spread around the globe. It was approved that muscle sprains, muscular and joint pain can be effectively relieved by hot herbal compress treatment [2-4]. The herbal compress treatment is thus considered as an elaborative practice contributed to its aromatherapy, thermal therapy and herbal therapy. As its name implies, herbal ball compress is a spherical shape cotton pouch with a handle on top. There are variety of herbs in the ball for example Plai or Cassumunar ginger (Zingiber cassumunar Roxb. or Zingiber montanum (J. Koenig) Link ex A. Dietr.), turmeric (Curcuma longa L.), and camphor [5]. To use the herbal ball compress, it needs to be steamed for 1015 minutes [5] in order to allow heat transferring to the herbs and stimulate the isolation of essential active substances and volatile oils from herbal ingredients.

The effectiveness of thermal modality like herbal ball compress may depend on various factors. Duration of application and therapeutic temperature are among those influencing parameters. It has been suggested that the appropriate temperature for the use of thermotherapy to relieve muscular spasm is between 40 to $45^{\circ} \mathrm{C}$ [6]. In addition, in order to achieve the useful physiologic effect, heating

\footnotetext{
${ }^{\mathrm{a}}$ Corresponding author : tao_wasan@hotmail.com
} 
modalities should be applied for 20 to 30 minutes [7, 8]. In the therapeutic treatment, hot herbal ball is pressed with a rolling motion on the affected area for a while and taken off for muscular relaxation and moved to the next areas. Such procedure is repeated for 20 to 30 minutes to achieve effective result. It is supposed that the useful area of the herbal ball compress is located at the lower part while the rest which covers larger surface is responsible to heat loss. Thus, herbal ball compress cannot hold the suitable temperature as required.

Though the unique use of herbal ball compress offers several potential health benefits, a major consideration is convective heat loss which results in steadily decrease of temperature. Generally, two or three herbal balls compress are used in a single treatment: one is in use while the others are heated in steamer. Replacing with the hot and fresh herbal ball when the one in use starts to cool is a common approach, even though this is not an economical solution. Several researchers in Thailand put effort into keeping the herbal ball compress temperature at a desired level for longer time span. Electric herbal ball was patented in 2008 [9] and produced for commercial purpose. Before the use, herbal powder in a cotton bag is wrapped around a spherical ball with an electric heater installed inside. Operating temperature can be set and monitored from a separated controller unit. It should be noted that this device was designed to use with herbal powder whereas the capability to apply with dry herbs in ordinary form has not been reported. Thermal energy from chemical reaction is also exploited to heat herbal ball compress as exhibited in [10]. This invention is, however, not widely used due to a sense of complexity. In addition, information regarding temperature controlling has not been revealed.

According to the previous study and the invented products as reviewed above, there is a gap to improve the herbal ball compress in term of thermal performance. The aim of this study is to efficiently control the herbal ball compress temperature at a suitable level and, also, prolong its applying duration to fully achieve the clinical effects of the heat treatment. The modification on herbal ball compress is associated with adding material of high specific heat capacity and supplying heat sources by various schemes directly into the ball. The experimental results of the modified herbal ball compress will be compared with the traditional one. It is supposed that the redesigned herbal ball compress would fulfil the deficiency of original product. Moreover, it is an opportunity to upgrade local brands to be in favoured worldwide.

\section{Material and method}

In this study, thermal performance of traditional herbal ball compress is compared with the ones which have been modified in various arrangements. The main ingredients of herbal ball compress are variety of dried herbs as has been described in the introduction section. The prepared herbs are wrapped by cotton cloth in spherical shape with a handle on top. Diameter and weight of the herbal balls compress in the test are about $22 \mathrm{~cm}$ and $200 \mathrm{~g}$, respectively. All tested material used in the current investigation are produced by Baan Tham Community Enterprise in Dok Khamtai District, Phayao Province, Thailand. Thermal performance of herbal ball compress will be observed through temperature profile with time evolution. Prior to perform the temperature measurement, determination of moisture content (MC) is conducted.

It is expected that MC in herbal ball compress may have effects on the experimental results. Thus, this parameter is evaluated corresponding to the Standard Test Methods for Direct Moisture Content Measurement of Wood and Wood-Base Materials (ASTM D4442-92) in Method A-Oven-Drying (Primary) [11]. To determine the MC, a force convection oven is used to dry herbal ball compress. Hot air temperature in the oven chamber will be controlled to maintain at $103 \pm 2^{\circ} \mathrm{C}$ throughout the drying process and the evaporated moisture is able to be vented via the device's ventilation system. Moisture content based on dry basis can be calculated as follows:

$$
M C(\%)=\frac{(A-B)}{B} \times 100
$$

where $A$ is original mass and $B$ is oven-dry mass. In equation (1), the oven-dry mass is obtain at the endpoint of drying process. The endpoint is assumed when the mass reduction within 3 hours of 
specimen is equal or less than two times the sensitivity of selected balance. An electric balance used in the current experiment has the sensitivity of $0.001 \mathrm{~g}$. Hence, the end point is achieve when the mass loss of herbal ball compress is less than $0.002 \mathrm{~g}$ in a three hours drying period.

Regarding experimental procedure, each herbal ball compress will be heated from room temperature until reaching around $90^{\circ} \mathrm{C}$ and keeping at this level for $10-15$ minutes to allow essential oil from herbs ingredient to be extracted. Then, heating is terminated to let the herbal ball temperature decrease. Time duration when the herbal ball decreases from $45^{\circ} \mathrm{C}$ to $40^{\circ} \mathrm{C}$ is recorded for subsequent analysis. In order to observe temperature variation of the herbal ball compress, four $\mathrm{K}$ type thermocouple probes are installed at different locations as indicated in Figure 1. The temperature measurement points are chosen corresponding to the usable area where the herbal ball is being compressed and rolled over patient's body. Herbal ball compress filled with materials of high specific heat capacity such as water balloons and white pebbles (river rock) are included in the test to compare with the traditional herbal ball. There are two sets of herbal balls filled with water balloon: one herbal ball is added with a water balloon of $120 \mathrm{~g}$ and another is added with six water balloons of $20 \mathrm{~g}$ each. For the herbal ball filled with rock, the mass of white pebbles is prepared approximately $120 \mathrm{~g}$. Besides adding extra materials, heat source supplied into herbal ball by different methods are also taken for the comparison. The heating suppliers chosen in this investigation are $60 \mathrm{~W}$ Peltier sheet, cable heater of $65 \mathrm{~W}$ rated power, 9 pieces of $5 \mathrm{~W}$ ceramic resistor and steam generated from an 800 $\mathrm{W}$ electric steamer. To supply steam into the herbal ball directly, a high heat resistance silicone tube of 3/4 inch nominal diameter is connected to the cover lid of steamer while another end of the tube is inserted into the herbal ball compress. Mass flow of steam can be controlled by a regulator installed on the steam tube.

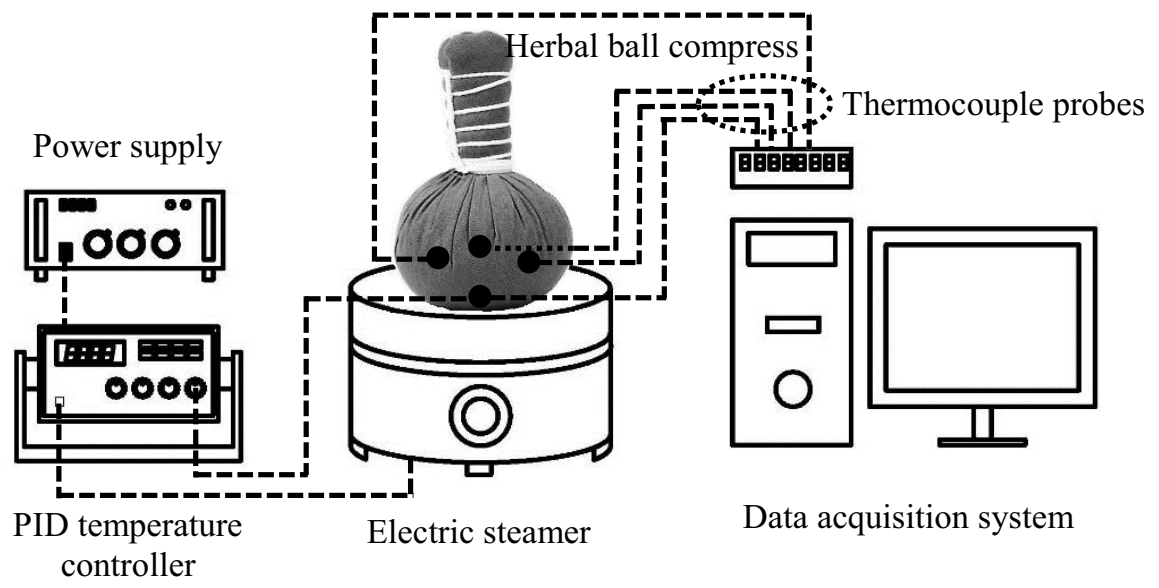

Figure 1. Illustration of experimental setup and a herbal ball in the experiment.

In this experiment, measured variables contain errors or uncertainties which can be categorised into two groups: precision uncertainty $(P)$ and bias uncertainty $(B)$. Regarding the determination for moisture of content from equation (1), its overall uncertainty $\left(U_{M C}\right)$ is evaluated at 95 percent confidential level by the following combination of a precision contribution to the uncertainty of MC $\left(P_{M C}\right)$ and a bias contribution to the uncertainty of $\mathrm{MC}\left(B_{M C}\right)[12]$ :

$$
U_{M C}=\sqrt{P_{M C}^{2}+B_{M C}^{2}}
$$

The precision contribution $\left(P_{M C}\right)$ and the bias contribution $\left(B_{M C}\right)$ can be found by the error propagation equation of Kline and McClintock [13] as shown in equation (3) and (4), respectively.

$$
P_{M C}^{2}=\left(\frac{\partial M C}{\partial A}\right)^{2} P_{A}^{2}+\left(\frac{\partial M C}{\partial B}\right)^{2} P_{B}^{2}
$$




$$
B_{M C}^{2}=\left(\frac{\partial M C}{\partial A}\right)^{2} B_{A}^{2}+\left(\frac{\partial M C}{\partial B}\right)^{2} B_{B}^{2}
$$

The precision limit $P_{A}$ and $P_{B}$ can each be calculated as 2 times the standard deviation of unsteadiness of a set of mass measurements of the original mass $(A)$ and oven-dry mass $(B)$ of the herbal ball compress, respectively. Regarding the bias limit $B_{A}$ and $B_{B}$, it cannot be directly determined by any statistical technique. However, it is estimated from a half of the readability of the digital balance [14]. According to the calculation, the overall uncertainty of moisture of content $\left(U_{M C}\right)$ is about $\pm 0.5 \%$. With the same methodology, the uncertainty of temperature measurement is evaluated at $\pm 0.53^{\circ} \mathrm{C}$.

\section{Experimental results and discussion}

In this study, the effort to prolong the temperature of herbal ball compress at an appropriate level is carried out by several techniques. It is supposed that material of high specific heat capacity could accomplish this intention. Water is a high specific heat capacity substance due to hydrogen bonding among water molecules. Thus, the quantity of water in the herb represented by percentage of moister content could have significant effects on thermal characteristic of the herbal ball compress.

Figure 2 shows the relationship between the time duration when the temperature of herbal ball compress decreases from $45^{\circ} \mathrm{C}$ to $40^{\circ} \mathrm{C}$ as a function of dry basis moisture content. The temperature range from $45^{\circ} \mathrm{C}$ to $40^{\circ} \mathrm{C}$ is in consideration here as it is the effective temperature for therapeutic treatment. Equation developed by data regression and R-squared are also depicted. Dashed line in the figure is drawn from the developed equation. It can be seen from the graph that at low percentage of moisture content the time duration when temperature of herbal ball compress decrease from $45^{\circ} \mathrm{C}$ to $40^{\circ} \mathrm{C}$ is shorter than that of the higher moisture content. Regarding specific heat property, it may represent the ability of material to store thermal energy and maintain its temperature. At temperature around $45^{\circ} \mathrm{C}$, specific heat capacity $\left(c_{p}\right)$ of water is $4.18 \mathrm{~kJ} / \mathrm{kg} \cdot \mathrm{K}$ whereas the average $c_{p}$ of wood based material is in the range of 0.77 to $1.78 \mathrm{~kJ} / \mathrm{kg} \cdot \mathrm{K}[15,16]$. An increase in moisture content improves the bulk specific heat capacity of herbal ball compress because the specific heat of the water is greater than that of herbs. Thus, at the specified temperature range, the herbal ball compress with higher moisture content could extend the time duration comparing to that of the drier one. From this observation, it is supposed that herbal ball compress with water balloon or white pebble rocks inside could imnrnve its thermal property. The investigation regarding this matter is revealed in Figure 3.

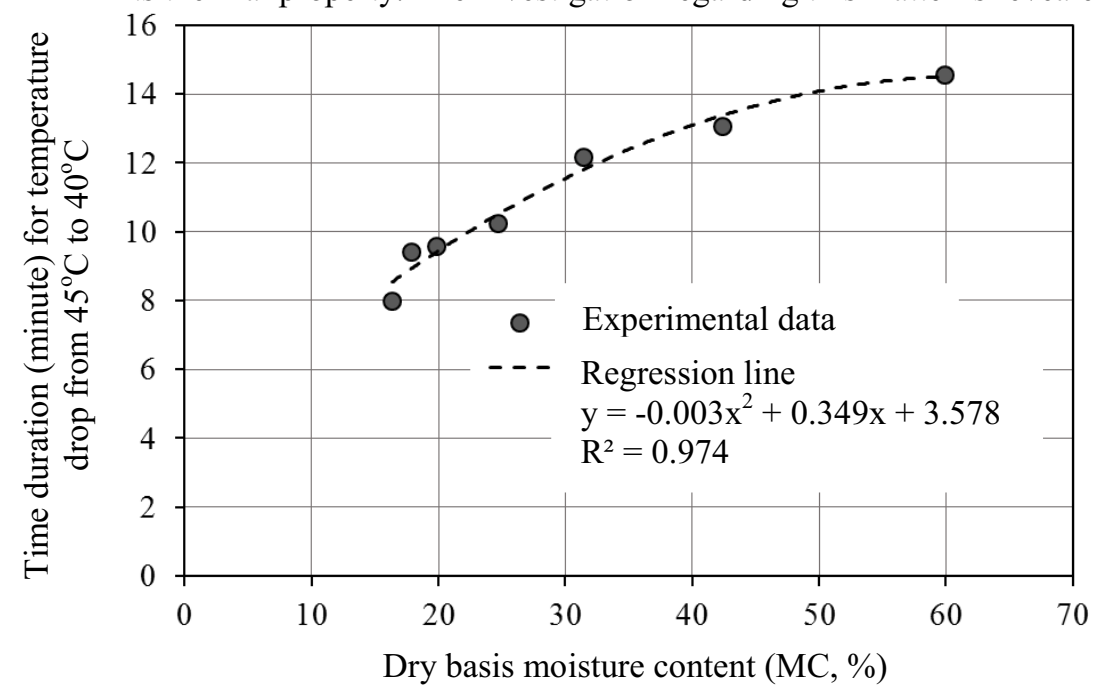

Figure 2. Dry basis moisture content (MC, \%) with time duration for temperature drop from $45^{\circ} \mathrm{C}$ to $40^{\circ} \mathrm{C}$. 


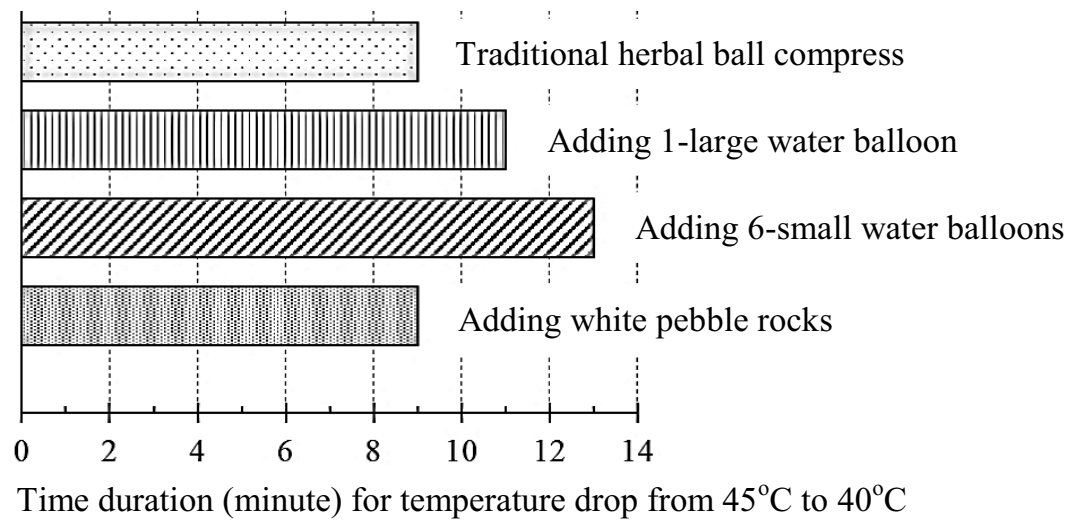

Figure 3. Time duration for temperature drop from $45^{\circ} \mathrm{C}$ to $40^{\circ} \mathrm{C}$ of herbal ball added with different materials.

From Figure 3, the bar graph represents time duration while temperature decreases from $45^{\circ} \mathrm{C}$ to $40^{\circ} \mathrm{C}$ on the traditional herbal ball comparing to the ones with added different materials. Water balloon inside the herbal ball can extend the time duration due to the higher specific heat capacity of water enhancing heat storing of the herbal ball. Six small water balloons provide the longer time than that with one large water balloon. This could be due to scattered location of small water balloons which is capable of absorbing more heat energy than one large water balloon. Regarding the pebble rocks, the result is similar to that of the traditional herbal ball as its mean specific heat capacity is only about $0.8 \mathrm{~kJ} / \mathrm{kg} \cdot \mathrm{K}[17]$.

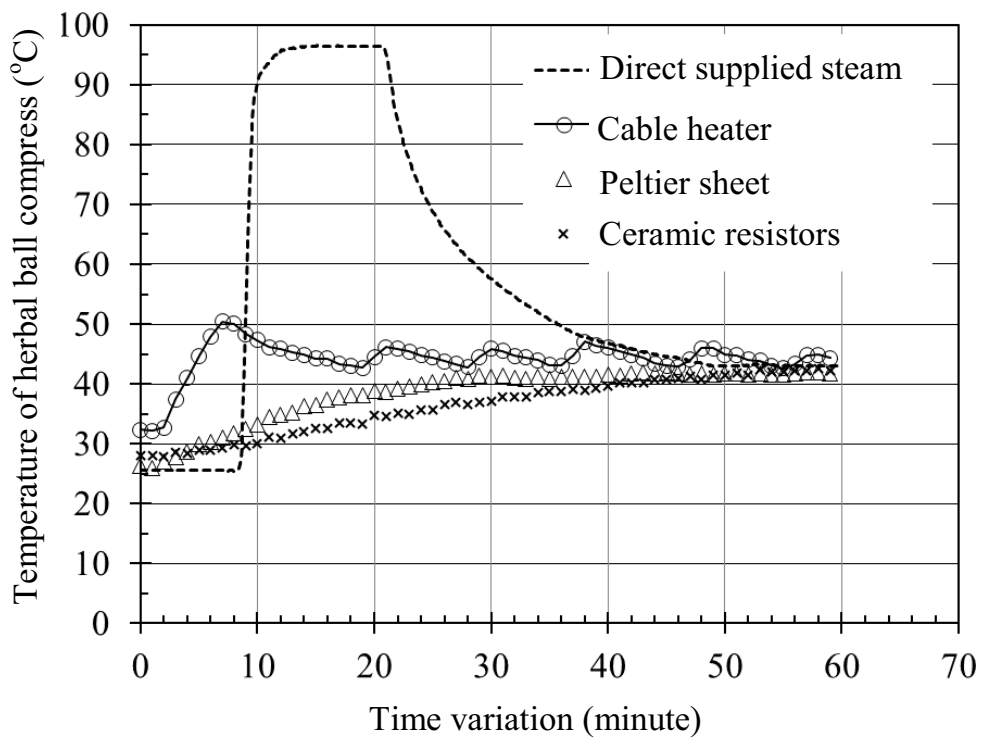

Figure 4. Temperature of herbal ball compress with time variation for various heating methods.

Although adding several small water balloons in the herbal ball could prolong the temperature to be within the desired level, it does not meet the suggested duration. In order to allow heat to increase the regional blood flow and to release volatile oils from herbs to help exerting anti-inflammatory action on the affected muscles, hot herbal compression should be applied around 20 - 30 minutes [7]. To achieve this time span, another options is installing heating source into the herbal ball. As shown in Figure 4, using cable heater, Peltier sheet and ceramic resistors as heating elements could raise herbal ball temperature to $45^{\circ} \mathrm{C}$. However, it is not sufficient to facilitate the release of volatile oils 
from herbal ingredients which required at up to $90^{\circ} \mathrm{C}$. Increasing rating power of the heating elements may damage the herbal ball as the heating will concentrate only on the elements' surface and herb ingredients may possibly be burned. For supplying steam directly into the herbal ball, the temperature profile shows that this method achieves thermal requirement for therapeutic heat treatment.

\section{Conclusions}

It was approved that herbal ball compress which is a blend of herbs could be used to relieve muscle sprains, joint pain and discomfort. To achieve therapeutic purpose, the herbal ball needs to be heated for 15 - 20 minutes to extract essential oils from herb ingredients. In addition, hot herbal compression at $40-45^{\circ} \mathrm{C}$ for $20-30$ minutes is recommended to receive the effective result. In traditional treatment procedure, two or more herbal balls compress are required as the temperature steadily decreases and it is difficult to control the temperature to be in the appropriate level. Herbal ball compress with added water balloons could extend time duration for the required temperature range. However, it is not long enough to meet the therapeutic suggestion. Heating modalities by cable heater, Peltier sheet and ceramic resistors are chosen for the test. According to their capabilities, they may not be suitable to be used as heat sources for herbal ball compress. Direct supplied steam is likely to be the suitable practice as the temperature of herbal ball compress can be controlled at a required condition. Moreover, a conventional electric steamer for household use with a little modification can be applied in this method. This will benefits the initial investment as only steam tube and a few accessories are additionally required.

\section{Acknowledgement}

The authors gratefully acknowledge the contributions of Mr.Pramote Ploydeelert, Mr.Wichian Saensong and Mr.Donlawat Hanyut for their helps on setting up a part of the experimental apparatus and a preliminary testing on the system capability. The authors also wish to express their appreciation to the reviewers and editors for their very useful comments and contributions.

\section{References}

1. V. Chokevivat, A. Chuthaputti. 6GCHP, pp.1-25 (2005)

2. J. Boonruab, N. Nimpitakpong, W. Damjuti, JEBIM, 23, pp. 1-8 (2018)

3. P. Sukonthasarn, THPJ, 1(1), pp. 23-35 (2004)

4. Institute of Thai Traditional Medicine, Thai Traditional Medicine and Health Care (2003)

5. T. Dhippayom, C. Kongkaew, N. Chaiyakunapruk, P. Dilokthornsakul, R. Sruamsiri, S. Saokaew, A. Chuthaputti, eCAM, 2015, 942378 (2015)

6. J. F. Lehmann, Therapeutic heat and cold, pp. 439-447 (1990)

7. P. S. Tepperman, M. Devlin, CFP, 32, pp. 1110 (1986)

8. M. Y. Kim, J. H. Kim, J. U. Lee, Y. M. Kim, J. A. Lee, N. M. Yoon, B. Y. Hwang, K. J. Kim, H. M. Lee, B. Kim, J Phys Ther Sci, 23, 5, pp. 797-801 (2011)

9. B. Khemjareun, PAT. 4209, Thailand (2008)

10. S. Upalee, S. Liawruangrath, PAT. 13508, Thailand (2018)

11. ASTM, ASTM D4442 (2007)

12. J. H. Kim, T. W. Simon, R. Viskanta, J Heat Transfer, 115, 1, pp. 5-6 (1993)

13. S.J. Kline, F.A. McClintock, Mech Eng, 75, pp. 3-8 (1953)

14. R.H. Dieck, W.G. Steele, G. Osolsobe, ASME PTC 19.1-2005 (2005)

15. Ł. Czajkowski, W. Olek, J. Weres, R. Guzenda, Wood Sci Technol, 50, 3, pp. 537-545 (2016)

16. M. Gupta, J. Yang, C. Roy, FUEL, 82, 8, pp. 919-927 (2003)

17. E. C. Robertson, B. S. Hemingway, USGS (1995) 